\title{
Fatty acid composition of nuts - implications for cardiovascular health
}

\author{
Emilio $\operatorname{Ros}^{1} *$ and José Mataix ${ }^{2}$ \\ ${ }^{1}$ Unitat de Lípids, Sevei d'Endocrinologia i Nutrició, Institut d'Investigacions Biomèdiques August Pi Sunyer, Hospital Clínic, \\ Barcelona, Spain \\ ${ }^{2}$ Instituto de Nutrición y Tecnología de los Alimentos, Universidad de Granada, Granada, Spain
}

\begin{abstract}
It is well established that, due to their high content of saturated fatty acids (SFA), the intake of meat and meat products is strongly associated with elevated blood cholesterol concentrations and an increased risk of hypertension, diabetes and cardiovascular diseases. Conversely, the intake of foods rich in unsaturated fatty acids, such as those contained in most vegetable fats and oils and oily fish, is associated with improved lipid profiles, a lower potency of intermediate biomarkers of atherosclerosis and lesser incidence of cardiovascular diseases. There are persuasive evidences that dietary substitution of monounsaturated fatty acids (MUFA) or n-6 polyunsaturated fatty acids (PUFA) for SFA lowers blood cholesterol and may have beneficial effects on inflammation, thrombosis, and vascular reactivity. MUFA may have an advantage over PUFA because enrichment of lipoprotein lipids with MUFA increases their resistance to oxidation. Marine n-3 PUFA have a number of anti-atherosclerotic effects, including anti-arrhythmic properties and, at relatively high doses, reduce serum triglycerides. These effects appear to be shared in part by vegetable n-3 PUFA. Nuts are natural foods rich in unsaturated fatty acids; most nuts contain substantial amounts of MUFA, while walnuts are especially rich in both n-6 and n-3 PUFA. Healthy fats in nuts contribute to the beneficial effects of frequent nut intake observed in epidemiological studies (prevention of coronary heart disease, diabetes, and sudden death) and in short-term feeding trials (cholesterol lowering, LDL resistance to oxidation, and improved endothelial function).
\end{abstract}

\section{Scientific interest of dietary fat}

Throughout the history of mankind, dietary fat has been the nutrient that has varied more in quantity and quality. Predictably, upward or downward changes in total fat intake have been closely related to those of socio-economic progress and food availability. In today's world, it is estimated that two billion people regularly consume meat and meat products in their diet, while four billion people, mostly malnourished, survive on a diet that is almost exclusively made up of vegetable foods. Small amounts of total fat, including animal fat and vegetable oils for culinary use, are consumed by underdeveloped societies, whereas wealthy populations consume important quantities of both animal fats and edible oils.

Since the end of the Second World War and during a long period of prosperity, developed Western populations have progressively increased fat intake to $40 \%$ of total energy or more (World Health Organization, 2002). Notably, a sizable proportion of this fat is from animal origin, rich in saturated fatty acids (SFA). In the pioneering Seven Countries Study (Keys, 1980), performed in the 1950s, a high intake of SFA was first observed to be strongly associated with increases of both blood cholesterol levels and rates of coronary heart disease. During the last 50 years, a consistent body of scientific evidence has accumulated supporting a direct relationship between the intake of meat and SFA and the development of cardiovascular diseases (reviewed by Hooper et al. 2001; Hu et al. 2001; Kris-Etherton et al. 2001; Mann, 2002). Epidemiological and clinical studies have also suggested that
SFA intake is associated with the risk of developing diabetes (Mann, 2002) and various types of cancer (Key et al. 2002). More recently, it has also been recognized that certain isomerized fatty acids produced during the manufacturing of commercial solid vegetable fats (trans fatty acids) are most detrimental to cardiovascular health (Ascherio et al. 1999).

In accordance with the persuasive evidence collected on the adverse effects of animal fat on both cardiovascular risk factors and clinical outcomes, nutrition advice for the treatment of hypercholesterolaemia, hypertension, obesity and diabetes has traditionally emphasized avoiding animal fats and replacing them with carbohydrate. However, given the high energy content of fats of any type $(9 \mathrm{kcal} / \mathrm{g}$ compared with $4 \mathrm{kcal} / \mathrm{g}$ for carbohydrate and protein) and the generalized perception that its consumption promotes obesity, usual dietary recommendations for health emphasize avoiding all kinds of fatty foods, not only those rich in SFA. This is despite the fact that scientific evidences have accumulated in the last two decades about the beneficial role on a number of cardiovascular risk factors of diets with a relatively high content of unsaturated fatty acids, such as those present in vegetable oils, nuts and fish (Hu \& Willett, 2002). Regarding marine n-3 polyunsaturated fatty acids (PUFA), prospective studies and clinical trials using mainly eicosapentaenoic acid (EPA, C20:5n-3) and docosahexaenoic acid (DHA, C22:6n-3) have provided consistent evidences of the beneficial effect on most pro-thrombotic cardiovascular risk factors (Calder, 2004; Schmidt et al. 2005a, 2005b), including inflammation (Calder, 2002). There are also increasing evidences for 
a salutary effect on cardiovascular risk of high intakes of $\alpha$-linolenic acid (C18:3n-3; ALA), the plant-derived n-3 PUFA that is the precursor of the longer chain and more unsaturated EPA and DHA in the body (Harris, 2005). One of the most heated debates in public health and nutrition has been precisely whether it was preferable to recommend carbohydrates or unsaturated fats to replace the energy derived from the SFA when intake is curtailed (Connors et al. 1997). Presently, the prevailing opinion among authorities is that, provided the diet contains both sufficient quantities and an appropriate balance of n-6 and n-3 PUFA (Wijendran \& Hayes, 2004), low-fat, high-carbohydrate diets and those relatively rich in total fat in which monounsaturated fatty acids (MUFA), mainly oleic acid (C18:1n-9), predominate are equally healthy (Kris-Etherton, 1999; Franz et al. 2002). As discussed below, the nutritional advice of high-MUFA diets for beneficial health effects is compatible with the frequent intake of nuts.

\section{Biological effects of fatty acids}

Since fat accounts for $50 \%$ or more of the energy provided by nuts, we will briefly review the biological effects of the different fatty acid classes, which have been evaluated in many clinical trials. The studies with the highest scientific quality have used a crossover design and isoenergetic substitution of the test nutrients to assess the effects on intermediate outcomes of the intake of fats and oils enriched in the fatty acids under study by comparison with those of an alternate fat source or carbohydrates.

\section{Effects on the blood lipid profile}

Many controlled clinical studies have assessed the quantitative effects of changes in dietary fat quality and quantity on the blood lipid profile (reviewed by Mensink \& Katan, 1992; Yu et al. 1995; Clarke et al. 1997; Mensink et al. 2003).

SFA intake has been repeatedly shown to raise the serum concentrations of total, LDL and HDL cholesterol and the cholesterol/HDL ratio. On the other hand, isoenergetic substitution of MUFA or PUFA of the n- 6 series (mainly linoleic acid, C18:2n-6) for SFA has the opposite effects. As for the possible mechanisms of these effects, animal studies consistently reveal that fats containing unsaturated fatty acids enhance hepatic receptor-dependent clearance of LDL and concomitantly reduce LDL cholesterol production (Woollett et al. 1992). Serum triglycerides are nonsignificantly reduced

\begin{tabular}{lccc} 
Fatty acids & LDL cholesterol & HDL cholesterol & Triglycerides \\
\hline Saturated & $\uparrow$ & $\uparrow$ & - or $\uparrow$ \\
Cis monounsaturated & $\downarrow$ & - or $\uparrow$ & $\downarrow$ \\
Polyunsaturated n-6 & $\downarrow$ & - or $\downarrow$ & $\downarrow$ \\
Polyunsaturated n-3 & $\uparrow *$ & - & $\downarrow$ \\
Trans & $\uparrow$ & $\downarrow$ & $\uparrow$ \\
\hline
\end{tabular}

$\uparrow$ increase, $\downarrow$ decrease, - no change, $*$ LDL composition changed towards larger, less dense particles.

Fig. 1. Effects of the different fatty acid classes on the lipid profile. when energy derived from SFA decreases (Yu-Poth et al. 1999) or when SFA are substituted for unsaturated fatty acids (Gardner \& Kraemer, 1995). On the other hand, when dietary carbohydrate is replaced by cis unsaturated fatty acids, LDL cholesterol levels do not change, but triglycerides are consistently lowered and HDL cholesterol rises. This is because of the well-known unfavourable effect of high carbohydrate intake on triglycerides and HDL cholesterol (Parks \& Hellerstein, 2000). It has been debated whether MUFA and n-6 PUFA have differential effects on the lipid profile. The recent meta-analysis of Mensink et al. (2003) signals slight differences favouring MUFA for raising HDL cholesterol and n-6 PUFA for lowering LDL cholesterol when isoenergetically replacing carbohydrates.

PUFA of the n-3 series have lipid effects that are specific for this fatty acid class. At an average intake of $4 \mathrm{~g} / \mathrm{d}$, marine n-3 PUFA reduce serum triglycerides by $25 \%$ in normal subjects and by $34 \%$ in hypertriglyceridemic subjects, without modifying HDL cholesterol, but variably increasing LDL cholesterol (Harris, 1997). The LDL cholesterol raising effect of n-3 fatty acids has also been observed after administration of smaller doses (Theobald et al. 2004). The n-3 fatty acids lower triglycerides by inhibiting the synthesis of VLDL in the liver. Improved triglyceride metabolism is followed by the formation of less dense LDL particles and an overall less atherogenic lipid profile (Griffin, 2001), thus offsetting any adverse effect from an LDL cholesterol elevation.

ALA, the n-3 PUFA of plant origin, has been less studied for lipid effects, which appear to be similar to those of the n-6 PUFA. Although the results from most small feeding trials suggest that ALA does not share the hypotriglyceridaemic effect of its marine counterparts (Sanderson et al. 2002), a recent crossover survey in a large population found that the consumption of total linolenic acid was inversely related to plasma triglyceride concentrations (Djoussé et al. 2003).

Isomeric trans fatty acids are produced by hydrogenation of unsaturated fatty acids during the manufacture of solid vegetable fats (margarines, shortenings, spreads and vegetable fats typical of fast foods). When ingested in significant amounts, the effects of trans fatty acids on the lipid profile are the most detrimental, since they both increase LDL cholesterol and lower HDL cholesterol relative to cis unsaturated fatty acids (Katan \& Zock, 1995). The intake of trans fatty acids contributes to an increased cardiovascular risk through other deleterious lipid effects, such as increased concentrations of triglycerides and lipoprotein(a) (Katan \& Zock, 1995; Ascherio et al. 1999).

The effects of the different fatty acids on the lipid profile are summarized in Fig. 1. Understandably, the principal dietary strategy for lowering LDL cholesterol levels is to replace cholesterol raising fatty acids (i.e. saturated and trans fatty acids) with dietary carbohydrate and/or unhydrogenated unsaturated fatty acids.

\section{Effects on other cardiovascular risk factors}

Although less investigated than the effects on the lipid profile, fatty acids also have non-lipid effects that are relevant for cardiovascular risk. Thus, SFA promote insulin resistance and the development of diabetes, while MUFA (Ros, 2003) 
and especially n-3 PUFA (Manco et al. 2004) appear to revert these deleterious effects. The fatty acid composition of skeletal muscle membranes influences insulin sensitivity, and both experimental work in rats and studies in humans have shown that the incorporation of highly unsaturated fatty acids into muscle membrane phospholipids, thereby increasing membrane fluidity, is associated with improved insulin action (Storlien et al. 1996). By regulating several transcription factors, highly unsaturated fatty acids also suppress lipogenic gene expression and enhance the expression of genes involved in fatty acid oxidation and thermogenesis (Clarke, 2004). While these favourable effects of PUFA (mostly n-3) on insulin sensitivity have been clearly demonstrated in animal models, further studies are required to confirm these findings in humans.

Except for the slight but consistent blood pressure lowering effect of n-3 PUFA (Geleijnse et al. 2002), the data are less solid on fatty acid intake and arterial hypertension (Hermansen, 2000). Recent epidemiological evidences from Mediterranean countries suggest that MUFA intake from olive oil is associated with lower blood pressure (Alonso et al. 2005). There is also limited evidence that consumption of MUFA is associated with beneficial effects on coagulation factors, inflammation and endothelial activation, albeit it is difficult to unravel some of these effects from those of other components of olive oil, the principal vehicle used for increasing MUFA intake in most studies (Pérez-Jiménez et al. 2002).

Dietary fatty acids are rapidly incorporated into lipoprotein lipids. While n-6 PUFA enrichment of LDL or other lipoproteins involved in lipid transport increases their susceptibility to oxidation (which is initiated in the double bonds of PUFA), enrichment of lipoprotein particles with less unsaturated oleic acid at the expense of linoleic acid enhances their resistance to oxidative stress, and is therefore another potential antiatherogenic effect of this fatty acid class (Parthasarathy et al. 1990; Reaven \& Witzum, 1996; Ramirez-Tortosa et al. 1999). On a molar basis, even if supplemented in relatively large amounts, n-3 PUFA enriches lipoprotein lipids to a much lesser extent than either n-6 PUFA or MUFA. Omega-3 PUFA generally do not increase LDL oxidizability. On the other hand, n-3 PUFA have clearly demonstrated anti-thrombotic, anti-inflammatory and anti-arrhythmic effects, thus possessing specific anti-atherosclerotic properties (Calder, 2002, 2004; Schmidt et al. 2005a, 2005b).

\section{Effects on vascular reactivity}

Finally, the profound effects of fatty acids on vasoreactivity need to be considered. Endothelial dysfunction is a critical event in atherogenesis that is implicated both in early disease and in advanced atherosclerosis, where it relates to perfusion abnormalities and the causation of ischaemic events (Bonetti et al. 2003). It is characterized by a decreased bioavailability of nitric oxide, the endogenous vasodilator synthesized from the amino acid L-arginine (Moncada \& Higgs, 1993), and increased expression of pro-inflammatory cytokines and cellular adhesion molecules. Endothelial injury caused by cardiovascular risk factors or atherosclerotic vascular disease reduces nitric oxide production and this is followed by arterial wall abnormalities, both functional (inhibition of vasodilatation or paradoxical vasoconstriction) and structural (smooth muscle cell growth and blood cell adhesion) that are responsible for the initiation, development and progression of atherosclerosis (Bonetti et al. 2003).

Food intake is an important factor that affects vascular reactivity. Short-term feeding trials have consistently shown that diets rich in SFA impair endothelial function (Brown \& Hu, 2001; West, 2001; Sanderson et al. 2004). Besides, a single fatty meal rich in SFA is usually followed by transient endothelial dysfunction in association with raised triglyceride-rich lipoproteins (De Koning \& Rabelink, 2002). Whether acute or chronic, these detrimental effects are counteracted by the administration of n-3 PUFA and other nutrients present in nuts, such as antioxidant vitamins and L-arginine (Brown \& Hu, 2001; West, 2001).

Studies with MUFA in relation to vasoactivity have been contradictory (Sanderson et al. 2004). However, a feeding trial showed improved endothelial function in hypercholesterolaemic patients who followed a Mediterranean diet containing abundant olive oil (Fuentes et al. 2001). Furthermore, oleic acid shares with marine n-3 PUFA the capacity to suppress pro-inflammatory cytokines and reduce expression of cell adhesion molecules (De Caterina et al. 2000). These are critical in recruiting circulating leucocytes to the vascular endothelium, an important event in the pathogenesis of endothelial dysfunction and atherosclerosis. These effects may be mediated through actions on intracellular signalling pathways, leading to reduced activation of transcription factors such as NF-кB (De Caterina et al. 2000). Nevertheless, the precise effects of unsaturated fatty acids on these critical cellular processes and their impact on cardiovascular risk are yet to be fully understood.

\section{Fatty acids from nuts}

With the exception of chestnuts, which contain little fat, nuts are fatty foods. Their total fat content ranges from $46 \%$ in cashews and pistachios to $76 \%$ in macadamia nuts (Table 1). However, the fatty acid composition of nuts is beneficial because the SFA content is low (4-16\%) and almost onehalf of the total fat content is made up of unsaturated fatty acids, MUFA (oleic acid) in most nuts, similar proportions of MUFA and PUFA (linoleic acid) in Brazil nuts, a predominance of PUFA over MUFA in pine nuts, and mostly PUFA, both linoleic acid and ALA, in walnuts.

With regard to walnuts, it must be underlined that they are the whole food with the highest content of ALA of all edible plants (Exler \&Weihrauch, 1986). As shown in Table 1, the proportion of linoleic acid to ALA in walnuts is $\approx 4: 1$. At the cellular level, these two fatty acids are substrates for the same desaturation and elongation enzymes in the biosynthetic pathway leading to eicosanoid production (Calder, 2004). Enzymatic competition has important biological repercussions when there is an imbalance in favour of one of the substrates. Linoleic acid can be converted into arachidonic acid and then metabolized into the $\mathrm{n}-6$ eicosanoids. These cellular mediators enhance platelet aggregation and are generally pro-inflammatory. Conversely, ALA is the precursor of the longer chain and more unsaturated EPA and DHA and their n-3 eicosanoid metabolites, which are less active and can partly antagonize the pro-inflammatory actions of the n-6 eicosanoids (Heller et al. 1998). Thus, considering that the balance of $\mathrm{n}-6$ 
Table 1. Average fatty acid composition of nuts (grams per $100 \mathrm{~g}$ )

\begin{tabular}{|c|c|c|c|c|c|c|}
\hline Nuts & Total fat & SFA & MUFA & PUFA & $18: 2 n-6$ & $18: 3 n-3$ \\
\hline Almonds & $50 \cdot 6$ & 3.9 & $32 \cdot 2$ & $12 \cdot 2$ & $12 \cdot 2$ & 0.00 \\
\hline Brazil nuts & $66 \cdot 4$ & $15 \cdot 1$ & 24.5 & $20 \cdot 6$ & $20 \cdot 5$ & 0.05 \\
\hline Cashews & $46 \cdot 4$ & $9 \cdot 2$ & $27 \cdot 3$ & $7 \cdot 8$ & $7 \cdot 7$ & 0.15 \\
\hline Hazelnuts & $60 \cdot 8$ & 4.5 & $45 \cdot 7$ & 7.9 & $7 \cdot 8$ & 0.09 \\
\hline Macadamia nuts & $75 \cdot 8$ & $12 \cdot 1$ & 58.9 & 1.5 & 1.3 & $0 \cdot 21$ \\
\hline Peanuts & $49 \cdot 2$ & $6 \cdot 8$ & 24.4 & $15 \cdot 6$ & $15 \cdot 6$ & 0.00 \\
\hline Pecans & $72 \cdot 0$ & $6 \cdot 2$ & $40 \cdot 8$ & $21 \cdot 6$ & $20 \cdot 6$ & 1.00 \\
\hline Pine nuts (dried) & 68.4 & 4.9 & $18 \cdot 8$ & $34 \cdot 1$ & $33 \cdot 2$ & 0.16 \\
\hline Pistachios & 44.4 & $5 \cdot 4$ & $23 \cdot 3$ & 13.5 & $13 \cdot 2$ & 0.25 \\
\hline Walnuts & $65 \cdot 2$ & $6 \cdot 1$ & 8.9 & $47 \cdot 2$ & $38 \cdot 1$ & $9 \cdot 08$ \\
\hline
\end{tabular}

Data for raw nuts, except when specified. SFA, saturated fatty acids; MUFA, monounsaturated fatty acids; PUFA, polyunsaturated fatty acids; $18: 2 n-6$, linoleic acid; $18: 3 n-3, \alpha$-linolenic acid. Source: US Department of Agriculture Nutrient Data Base at http://www.nal.usda.gov/fnic/cgi-bin/ nut_search.pl Accessed 29 December 2005.

and n-3 PUFA in the diet is a critical factor influencing cardiovascular health (Wijendran \& Hayes, 2004), walnut intake may contribute to a good balance by beneficially influencing eicosanoid production.

\section{Contribution of constituent fatty acids to the beneficial effects of nut intake}

Frequent nut intake has been associated with lesser rates of cardiovascular disease events and sudden death in observational studies of large cohorts and with a consistent hypocholesterolaemic effect in short-term feeding trials (reviewed in this supplement by Sabaté \& Kelly, 2006 and Griel \& Kris-Etherton, 2006). Also, a prospective cohort study of women (Jiang et al. 2002) found that the frequency of nut or peanut butter consumption had an inverse association with the risk of developing type- 2 diabetes. Nuts are complex food matrices containing diverse nutrients, minerals, antioxidants and other phytochemicals that may favourably influence human physiology, a reason why these benefits may reasonably be attributed to the whole rather than the parts. With this premise in mind, we will discuss the extent to which the fatty acid component of nuts might contribute to the salutary health effects associated with their consumption.

\section{Reduction of cardiovascular morbidity and mortality}

The mechanisms whereby frequent nut intake affords protection for cardiovascular diseases are probably multiple, depending on the diverse potentially healthy components of nuts. There are three possible reasons why the fatty acid profile of nuts might contribute to this beneficial effect:

1. When consuming nuts, which are high-energy foods rich in unsaturated fatty acids, there is a satiety effect that suppresses hunger and limits intake of other energy-dense foods (Kirkmeyer \& Mattes, 2000). This same mechanism might explain why persons who consume nuts frequently do not gain weight. The foods that are displaced by this satiating effect tend to be detrimental for cardiovascular health because they are rich in animal protein, SFA, trans fatty acids and simple sugars (Jaceldo-Siegl et al. 2004)
2. Intake of unsaturated fatty acids with nuts is intrinsically cardio protective (Kris-Etherton, 1999; Kris-Etherton et al. 2001).

3. N-3 PUFA from nuts, mainly ALA in walnuts, protect from fatal coronary heart disease and sudden death due to their anti-arrhythmic properties (Leaf et al. 2003; Albert et al. 2005). This specific effect of n-3 PUFA was incriminated in the outstanding protection from coronary death observed in the Lyon Diet Heart Study, a secondary prevention trial in which the main intervention was a modified Mediterranean diet supplemented with an ALA-enriched margarine (De Lorgeril et al. 1999). It is now increasingly recognized that dietary ALA may have a number of cardioprotective actions (Harris, 2005).

\section{Cholesterol-lowering effect}

As reviewed by Griel \& Kris-Etherton (2006) in this supplement and by others elsewhere (Mukuddem-Petersen et al. 2005), numerous controlled feeding trials have convincingly shown that the daily intake of manageable allowances of a variety of nuts for periods of 4-8 weeks has a clear cholesterol-lowering effect. The magnitude of the reduction in total and LDL cholesterol concentrations observed in these studies can be attributed in part to exchanges of MUFA and PUFA in the nut-enriched diets for SFA in the comparator diets, as predicted by typical equations (Mensink \& Katan, 1992; Yu et al. 1995; Clarke et al. 1997). However, the cholesterol-lowering effect observed after nut supplementation has often been higher than that predicted on the basis of the fatty acid profiles of the test diets (Griel \& Kris-Etherton, 2006), indicating that nuts may contain other bioactive components capable of reducing blood cholesterol. The fact that fat isolated from almonds, either as oil (Hyson et al. 2002) or butter (Spiller et al. 2003), has a hypocholesterolaemic efficacy similar to that of the whole nut suggests that the constituents responsible for this effect are associated with the lipid fraction. As discussed by Segura et al. (2006) in this supplement, the best candidate molecules are phytosterols.

In a feeding trial with walnuts, LDL particles enriched with PUFA from walnuts were cleared more efficiently by hepatic cells than LDL obtained during the control Mediterranean diet. The accelerated clearance of LDL during the walnut 
diet was directly related to the ALA content of the LDL core, suggesting a possible mechanism whereby the unique lipid fraction of walnuts might help lower blood cholesterol (Muñoz et al. 2001).

\section{Lipoprotein oxidation}

Because a substantial fraction of the fat contained in most nuts is made up of MUFA, enrichment of lipoprotein lipids with these fatty acids following nut intake would either not change or decrease their susceptibility to oxidation (Reaven \& Witzum, 1996). Conversely, the high PUFA content of walnuts might be associated with detrimental changes of lipoprotein oxidisability. The resistance of LDL to an in vitro oxidative stress was a secondary outcome in three feeding trials comparing walnut diets with other healthy diets for effects on cardiovascular risk markers, and none of them found between-diet differences (Zambón et al. 2000; Iwamoto et al. 2002; Ros et al. 2004). In all likelihood, tocopherols and other antioxidants present in walnuts (and in all nuts) counteracted the potentially adverse effects of increasing the LDL content of PUFA, a critical substrate for oxidation processes.

\section{Vascular reactivity}

A recent feeding trial study showed that, by comparison with a Mediterranean diet, a walnut diet attenuated the endothelial dysfunction associated with hypercholesterolaemia (Ros et al. 2004). By analogy with the improvement of endothelial function observed after supplementation of marine n-3 PUFA (Brown \& Hu, 2001; West, 2001; Sanderson et al. 2004), this beneficial effect of walnuts may be ascribed in part to their high ALA content. Recent clinical studies have shown that diets enriched with ALA from walnuts or other sources reduce circulating levels of cytokines and other inflammatory mediators involved in endothelial activation (Rallidis et al. 2004; Zhao et al. 2004). Walnut feeding also reduced the expression of endothelin-1, a potent endothelial activator, in an animal model of accelerated atherosclerosis (Davis et al. 2006). To our knowledge, no vascular reactivity studies have been performed after consumption of diets enriched with other nuts. However, they might be expected to also show beneficial effects because all nuts contain substantial amounts of molecules that can favourably influence vasoactivity, such as L-arginine (Segura et al. 2006) and antioxidants (Blomhoff et al. 2006).

\section{Conclusions}

Fat accounts for almost $50 \%$ of the weight in nuts, which are one of the natural plant foods richest in fat after vegetable oils. However, the fat of nuts is mainly composed of unsaturated fatty acids. Replacement of fatty foods in the diet with nuts reduces blood cholesterol and has other beneficial effects on the cardiovascular risk profile. MUFA, mainly oleic acid, is predominant in almonds, cashews, hazelnuts, macadamia nuts, peanuts, pecans and pistachios; Brazil nuts and pine nuts contain similar proportions of MUFA and PUFA (linoleic acid); and walnuts are rich in both linoleic acid and ALA, the plant n-3 fatty acid. The fatty acids from nuts are important contributors to the beneficial health effects of frequent nut consumption, namely protection from the development of coronary heart disease and sudden cardiac death, lowering blood cholesterol, preservation or enhancement of LDL resistance to oxidation and improvement of endothelial function.

\section{Acknowledgements}

This work was supported in part by grants from the Spanish Health Ministry to Dr Emilio Ros (FIS C03/01 and G03/140).

\section{References}

Albert CM, Oh K, Whang W, Manson JAE, Chae CU, Stampfer MJ, Willett WC \& Hu FB (2005) Dietary $\alpha$-linolenic acid intake and risk of sudden cardiac death and coronary heart disease. Circulation 112, 3232-3238.

Alonso A, Ruiz-Gutierrez V \& Martínez-González MA (2006) Monounsaturated fatty acids, olive oil and blood pressure: epidemiological, clinical and experimental evidence. Publ Health Nutr 9 , $251-257$.

Ascherio A, Katan MB, Zock PL, Stampfer MJ \& Willett WC (1999) Trans fatty acids and coronary heart disease. N Engl J Med 340, 1994-1998.

Blomhoff R, Carlsen MH, Frost Anderson L \& Jacobs DR (2006) Health benefits of nuts: potential role of antioxidants. $\mathrm{Br} J \mathrm{Nutr}$ 96, suppl. 2, S52-S60.

Bonetti PO, Lerman LO \& Lerman A (2003) Endothelial dysfunction: a marker of atherosclerotic risk. Arterioscler Thromb Vasc Biol 23, $168-175$.

Brown AA \& Hu FB (2001) Dietary modulation of endothelial function: implications for cardiovascular disease. Am J Clin Nutr 73, 673-686.

Calder PC (2002) Dietary modification of inflammation with lipids. Proc Nutr Soc 61, 345-358.

Calder PC (2004) n-3 Fatty acids and cardiovascular disease: evidence explained and mechanisms explored. Clin Sci 107, 1-11.

Clarke SD (2004) The multi-dimensional regulation of gene expression by fatty acids: polyunsaturated fats as nutrient sensors. Curr Opin Lipidol 15, 13-18.

Clarke R, Frost C, Collins R, Appleby P \& Peto R (1997) Dietary lipids and blood cholesterol: quantitative meta-analysis of metabolic ward studies. Br Med J 314, 112-117.

Connors WE, Connors SL, Katan MB, Grundy SM \& Willett WC (1997) Clinical debate. Should a low-fat, high-carbohydrate diet be recommended for everyone? $N$ Engl J Med 337, 562-567.

Davis P, Valacchi G, Pagnin E, Shao Q, Gross HB, Calo L \& Yokoyamaz W (2006) Walnuts reduce aortic ET-1 mRNA levels in hamsters fed a high-fat, atherogenic diet. J Nutr 136, 428-432.

De Caterina R, Liao JK \& Libby P (2000) Fatty acid modulation of endothelial activation. Am J Clin Nutr 71, 213S-223S.

De Koning EJP \& Rabelink TJ (2002) Endothelial function in the postprandial state. Atherosclerosis Suppl 3, 11-16.

De Lorgeril M, Salen P, Martin JL, Monjaud I, Delaye J \& Mamelle N (1999) Mediterranean diet, traditional risk factors, and the rate of cardiovascular complications after myocardial infarction. Circulation 99, 779-785.

Djoussé L, Hunt SC, Arnett DK, Province MA, Eckfeldt JH \& Ellison RC (2003) Dietary linolenic acid is inversely associated with plasma triacylglycerol: the National Heart, Lung, and Blood Institute Family Heart Study. Am J Clin Nutr 78, 1098-1102.

Exler J \& Weihrauch JL (1986) Provisional table on the content of omega-3 fatty acids and other fat components in selected foods. 
Washington, DC: US Department of Agriculture (Publication HNIS/PT-103).

Franz MJ, Bantle JP, Beebe CA, Brunzell JD, Chiasson JL, Garg A, Holzmeister LA, Hoogwerf B, Mayer-Davis E, Mooradian AD, Purnell JQ \& Wheeler M; American Diabetes Association (2004) Nutrition principles and recommendations in diabetes. Diabetes Care 27, S36-S46.

Fuentes F, López-Miranda J, Sánchez E, et al. (2001) Mediterranean and low-fat diets improve endothelial function in hypercholesterolemic men. Ann Intern Med 134, 1115-1119.

Gardner CD \& Kraemer HC (1995) Monounsaturated versus polyunsaturated dietary fat and serum lipids. Arterioscler Thromb Vasc Biol 15, 1917-1927.

Geleijnse JM, Giltay EJ, Grobbee DE, Donders ART \& Kok FJ (2002) Blood pressure response to fish oil supplementation: meta-regression analysis of randomized trials. J Hypertens 20 , 1493-1499.

Griel AE \& Kris-Etherton PM (2006) Tree Nuts and the Lipid Profile: A Review of Clinical Studies. Br J Nutr 96, suppl. 2, S68-S78.

Griffin BA (2001) The effect of n-3 fatty acids on low density lipoprotein subfractions. Lipids 36, Suppl, S91-S97.

Harris WS (1997) n-3 fatty acids and serum lipoproteins: human studies. Am J Clin Nutr 66, 1645S-1654S.

Harris WS (2005) Alpha-linolenic acid. A gift from the land? Circulation 111, 2872-2874.

Heller A, Koch T, Schmeck J \& van Ackern K (1998) Lipid mediators in inflammatory disorders. Drugs 55, 487-496.

Hermansen K (2000) Diet, blood pressure and hypertension. Br J Nutr 83, S113-S119.

Hooper L, Summerbell CD, Higgins JP, Thompson RL, Capps NE, Smith GD, Riemersma RA \& Ebrhim S (2001) Dietary fat intake and prevention of cardiovascular disease: a systematic review. Br Med J 322, 757-763.

Hu FB \& Willett WC (2002) Optimal diets for prevention of coronary heart disease. JAMA 288, 2569-2578.

Hu FB, Manson JE \& Willett WC (2001) Types of dietary fat and risk of coronary heart disease: a critical review. J Am Coll Nutr 20, $5-19$.

Hyson DA, Schneeman BO \& Davis PA (2002) Almonds and almond oil have similar effects on plasma lipids and LDL oxidation in healthy men and women. $J$ Nutr 132, 703-707.

Iwamoto M, Imaizumi K, Sato M, Hirooka Y, Sakai K, Takeshita A \& Kono M (2002) Serum lipid profiles in Japanese women and men during consumption of walnuts. Eur J Clin Nutr 56, 629-637.

Jaceldo-Siegl K, Sabaté J, Rajaram S \& Fraser GE (2004) Long-term almond supplementation without advice on food replacement induces favourable nutrient modifications to the habitual diets of free-living individuals. Br J Nutr 92, 533-540.

Jiang R, Manson JE, Stampfer MJ, Liu S, Willett WC \& Hu FB (2002) Nut and peanut butter consumption and risk of type 2 diabetes in women. JAMA 288, 2554-2560.

Katan MB \& Zock PL (1995) Trans fatty acids and their effects on lipoproteins in humans. Anпи Rev Nutr 15, 473-493.

Kelly JH \& Sabaté J (2006) Nuts and Coronary Heart Disease: an epidemiological perspective. Br J Nutr 96, suppl. 2, S61-S67.

Key TJ, Allen NE, Spencer EA \& Travis RC (2002) The effect of diet on risk of cancer. Lancet 360, 861-868.

Keys A (1980) Seven Countries: a Multivariate Analysis of Death and Coronary Heart Disease. Cambridge, MA: Harvard University Press.

Kirkmeyer SV \& Mattes RD (2000) Effects of food attributes on hunger and food intake. Int J Obes Relat Metab Disord 24, $1167-1175$.

Kris-Etherton P, Daniels SR, Eckel RH, et al. (2001) Summary of the Scientific Conference on Dietary Fatty Acids and Cardiovascular
Health. Conference Summary from the Nutrition Committee of the American Heart Association. Circulation 103, 1034-1039.

Kris-Etherton PM.AHA Science Advisory (1999) Monounsaturated fatty acids and risk of cardiovascular disease. Circulation 100, $1253-1258$.

Leaf A, Kang JX, Xiao YF \& Billman GE (2003) Clinical prevention of sudden cardiac death by n-3 polyunsaturated fatty acids and mechanism of prevention of arrhythmias by n-3 fish oils. Circulation 107, 2646-2652.

Manco M, Calvani M \& Mingrone G (2004) Effects of dietary fatty acids on insulin sensitivity and secretion. Diabetes Obes Metab 6, 402-413.

Mann JI (2002) Diet and risk of coronary heart disease and type 2 diabetes. Lancet 360, 783-789.

Mensink RP \& Katan MB (1992) Effect of dietary fatty acids on serum lipids and lipoproteins. A meta-analysis of 27 trials. Arterioscler Thromb 12, 911-919.

Mensink RP, Zock PL, Kester AD \& Katan MB (2003) Effects of dietary fatty acids and carbohydrates on the ratio of serum total to HDL cholesterol and on serum lipids and apolipoproteins: a meta-analysis of 60 controlled trials. Am J Clin Nutr 77, 1146-1155.

Moncada S \& Higgs A (1993) The L-arginine-nitric oxide pathway. N Engl J Med 329, 2002-2012.

Mukkudem-Petersen J, Oosthuizen W \& Jerling JC (2005) A systematic review of the effects of nuts on blood lipid profiles in humans. J Nutr 135, 2082-2089.

Muñoz S, Merlos M, Zambón D, Rodríguez C, Sabaté J, Ros E \& Laguna JC (2001) A walnut-enriched diet increases the association of LDL from hypercholesterolemic men to human hepatoma HEPG2 cells. J Lipid Res 42, 2069-2076.

Parks EJ \& Hellerstein MK (2000) Carbohydrate-induced hypertriacylglycerolemia: historical perspective and review of biological mechanisms. Am J Clin Nutr 71, 412-433.

Parthasarathy S, Khoo JC, Miller E, Barnett J, Witztum JL \& Steinberg D (1990) Low density lipoprotein rich in oleic acid is protected against oxidative modification: implications for dietary prevention of atherosclerosis. Proc Natl Acad Sci USA 87, 3894-3898.

Pérez-Jiménez F, López-Miranda J \& Mata P (2002) Protective effect of dietary monounsaturated fat on arteriosclerosis: beyond cholesterol. Atherosclerosis 163, 385-398.

Rallidis LS, Paschos P, Papaioannou ML, Liakos GK, Panagiotakos DB, Anastasiadis G \& Zampelas A (2004) The effect of diet enriched with alpha-linolenic acid on soluble cellular adhesion molecules in dyslipidaemic patients. Atherosclerosis 174, $127-132$.

Ramirez-Tortosa MC, Urbano G, López-Jurado M, Nestares T, Gomez MC, Mir A, Ros E, Mataix J \& Gil A (1999) Extravirgin olive oil increases the resistance of LDL to oxidation more than refined olive oil in free-living men with peripheral vascular disease. J Nutr 129, 2177-2183.

Reaven PD \& Witzum JL (1996) Oxidized low density lipoproteins in atherogenesis: role of dietary modification. Аnпu Rev Nutr 16, $51-71$.

Ros E (2003) Dietary cis-monounsaturated fatty acids and metabolic control in type 2 diabetes. Am J Clin Nutr 78, 617S-625S.

Ros E, Núñez I, Pérez-Heras A, Serra M, Gilabert R, Casals E \& Deulofeu R (2004) A walnut diet improves endothelial function in hypercholesterolemic subjects. Circulation 109, $609-1614$

Sanderson P, Finnegan YE, Williams CM, Calder PC, Birdge GC, Wootton SA, Griffin BA, Millward DJ, Pegge NC \& Bemelmans WJE (2002) UK Food Standards Agency $\alpha$-linolenic acid workshop. Br J Nutr 88, 573-579.

Sanderson P, Olthof M, Grimble RF, Calder PC, Griffin BA, de Roos NM, Belch JJF, Muller DPR \& Vita JA (2004) Dietary lipids and 
vascular function: UK Food Standards Agency workshop report Br J Nutr 91, 491-500.

Schmidt EB, Arnesen H, De Caterina R, Rasmussen LH \& Kristensen SD (2005a) Marine n-3 polyunsaturated fatty acids and coronary heart disease. Part I. Background, epidemiology, animal data, effects on risk factors and safety. Thromb Res 115, 163-170.

Schmidt EB, Arnesen H, Christensen JH, Rasmussen LH, Kristensen SD \& De Caterina R (2005b) Marine n-3 polyunsaturated fatty acids and coronary heart disease. Part II: Clinical trials and recommendations. Thromb Res 115, 257-262.

Segura R, Javierre C, Lizarraga A \& Ros E (2006) Other relevant components of nuts: phytosterols, folate, and minerals. $\mathrm{Br} J$ Nutr 96, suppl. 2, S36-S44.

Spiller GA, Miller A, Olivera K, Reynolds J, Miller B, Morse SJ, Dewell A \& Farquhar JW (2003) Effects of plant-based diets high in raw or roasted almonds, or roasted almond butter on serum lipoproteins in humans. $J$ Am Coll Nutr 22, 195-200.

Storlien LH, Pan DA, Kriketos AD, O'Connor J, Caterson ID, Cooney GJ, Jenkins AB \& Baur LA (1996) Skeletal muscle membrane lipids and insulin resistance. Lipids 31, S261-S265.

Theobald HE, Chowienczyk PJ, Whittall R, Humphries SE \& Sanders TAB (2004) LDL cholesterol-raising effect of low-dose docosahexaenoic acid in middle-aged men and women. Am J Clin Nutr 79, $558-563$.

West SG (2001) Effect of diet on vascular reactivity: an emerging marker for vascular risk. Curr Atheroscler Rep 3, 446-455.
Wijendran V \& Hayes KC (2004) Dietary n-6 and n-3 fatty acid balance and cardiovascular health. Апnи Rev Nutr 24, 597-615.

Woollett LA, Spady DK \& Dietschy JM (1992) Saturated and unsaturated fatty acids independently regulate low density lipoprotein receptor activity and production rate. J Lipid Res 33, 77-88.

World Health Organization (2002) Globalization Diet and Non Communicable Diseases. (NLM Classification QT 235). Geneva: World Health Organization.

Yu S, Derr J, Etherton TD \& Kris-Etherton PM (1995) Plasma cholesterol-predictive equations demonstrate that stearic acid is neutral and monounsaturated fatty acids are hypocholesterolemic. Am J Clin Nutr 61, 1129-1139.

Yu-Poth S, Zhao G, Etherton T, Naglak M, Jonnalagadda S \& KrisEtherton PM (1999) Effects of the National Cholesterol Education Program's Step I and Step II dietary intervention programs on cardiovascular disease risk factors: a meta-analysis. Am J Clin Nutr 69, 632-646.

Zambón D, Sabaté J, Muñoz S, Campero B, Casals E, Merlos M, Laguna JC \& Ros E (2000) Substituting walnuts for monounsaturated fat improves the serum lipid profile of hypercholesterolemic men and women: a randomized crossover trial. Ann Intern Med 132, 538-546.

Zhao G, Etherton TD, Martin KR, West SG, Gillies PJ \& Kris-Etherton PM (2004) Dietary $\alpha$-linolenic acid reduces inflammatory and lipid cardiovascular risk factors in hypercholesterolemic men and women. J Nutr 134, 2991-2997. 